\title{
Performance of the equations to estimate the glomerular filtration rate in Mexican patients receiving kidney
} transplantation

\author{
Jaime Antonio Borjas-García, ${ }^{1}$ Everardo Lugo-Vega, ${ }^{1}$ Lilia María de Guadalupe Llamazares-Azuara ${ }^{1}$ and \\ Marco Ulises Martínez-Martínez ${ }^{2 *}$ \\ ${ }^{1}$ Hospital Central "Dr. Ignacio Morones Prieto", Department of Nephrology; ${ }^{2}$ Instituto Mexicano del Seguro Social, Department of Internal Medicine. \\ San Luis Potosí, Mexico
}

\begin{abstract}
Introduction: The management of kidney transplant recipients requires glomerular filtration rate (GFR) monitoring, which is an indicator of graft primary function and patient survival. Objective: To evaluate the performance of different creatinine or cystatin-based formulas in the estimation of glomerular filtration rate in Mexican patients receiving kidney transplantation. Method: 30 transplant recipients were included, in whom the glomerular filtration rate was measured by means of iothalamate, and was also calculated using seven equations based on cystatin or creatinine. Results: The formula with the best performance was the one proposed by the chronic kidney disease epidemiology collaboration (CKD-EPI), with a bias of $-2.4 \mathrm{~mL} / \mathrm{min} / 1.73 \mathrm{~m}^{2}$ and an accuracy of 9.6; $96.7 \%$ of patients were within $30 \%$ of the measured GFR. The second best formula was the modification of diet in renal disease (MDRD) equation. Cystatin-based equations showed a poor performance. Conclusions: Our study suggests that, in Mexican patients receiving kidney transplantations, the best equations to estimate GFR are the CKD-EPI and MDRD equations.
\end{abstract}

KEY WORDS: Glomerular filtration rate. Kidney transplantation. Kidney function. Chronic Kidney Disease Epidemiology Collaboration Modification of Diet in Renal Disease. Creatinine clearance.

\section{Introduction}

Kidney transplantation is the treatment of choice in patients with chronic kidney disease, it is more effective and less costly than replacement therapy. ${ }^{1,2}$ Management of transplant recipient patients requires glomerular filtration rate (GFR) assessment, which is an indicator of graft primary function and long-term survival; ${ }^{3}$ moreover, GFR is an independent risk factor for cardiovascular mortality, ${ }^{4}$ which is the leading cause of death in kidney transplant recipients. ${ }^{5}$

GFR estimation should be as accurate as possible and, in this sense, the gold standard is inulin; however, owing to the difficulties for measuring GFR by this method, different creatinine or cystatin-based equations have been proposed. ${ }^{6}$ Creatinine has limitations for being the ideal GFR marker because it depends on muscle mass, tubular secretion and others; cystatin can also show variations depending on the method by means of which it is measured and might have variations in patients with hypothyroidism, cirrhosis or receiving certain medications. ${ }^{7}$ For that reason, it is suggested that all equations should be assessed in populations other than those where they were developed, calculating accuracy, precision and bias. ${ }^{6}$

The purpose of this study was to assess the performance in the estimation of kidney function with creatinine clearance $(\mathrm{CrCl})$ and with the Cockcroft-Gault
Correspondence:

*Marco Ulises Martínez-Martínez

E-mail: marcomtzmtz@ hotmail.com
Date of reception: 11-04-2018

Date of acceptance: 24-01-2019

DOI: 10.24875/GMM.M18004335
Gac Med Mex. 2019;155:206-210

Contents available at PubMed www.gacetamedicademexico.com 
(C-G), ${ }^{8}$ Modification of Diet in Renal Disease (MDRD), ${ }^{9}$ Chronic Kidney Disease Epidemiology Collaboration (CKD-EPI), ${ }^{10}$ Mayo Clinic Quadratic (MCQ) equation, ${ }^{11}$ Stevens-3 (third equation based on cystatin and creatinine according to Stevens et al. $)^{12}$ and CKD-EPI cystatin/creatinine (CKD-EPI Cys-Cr) formulas ${ }^{13}$ in kidney transplant recipients under the care of the outpatient clinic of the "Dr. Ignacio Morones Prieto" Central Hospital Nephrology Division, in San Luis Potosí, Mexico.

\section{Method}

Patients older than 18 years, who were renal transplantation recipients, and who were under the care of the Central Hospital "Dr. Ignacio Morones Prieto" Nephrology Division were included. Patients who attended the nephrology outpatient clinic were invited to participate in the study, which was approved by the Ethics Committee; those who agreed to participate had to sign the informed consent form. Patients with at least three months from having received the kidney transplant were included. Pregnant patients, patients with a history of acute rejection, on replacement therapy with peritoneal dialysis or hemodialysis, chronic liver disease, hypothyroidism or allergy to the contrast medium were excluded. Creatinine values were standardized according to Roche enzymatic method. Cystatin $C$ was measured using the enzyme-linked immunosorbent assay (ELISA) method.

The reference standard was iothalamate clearance, which was measured using a laboratory standard method: ${ }^{14}$ after oral hydration with four and six glasses of water, patients received a non-radiolabeled iothalamate subcutaneous injection (Conray ${ }^{\circledR}$ ); after a one-hour balance period, the patient urinated, the first sample was taken and urinary collection was started. An ultrasound was performed in order to verify complete emptying of the bladder: no patient had urinary retention. After urine collection (approximately 45 to 60 minutes), a second sample was obtained. GFR was calculated with the clearance equation:

\section{VIoU/loP}

Where:

$\mathrm{V}=$ urinary flow

$\mathrm{IOU}=$ iothalamate urinary concentration

IOP = iothalamate plasma concentration

The mean of the two serum samples and a urinary sample for iothalamate via capillary electrophoresis was used. All GFR measurements were standardized for $1.73 \mathrm{~m}^{2}$ of body surface area, multiplying by 1.73 and dividing by body surface area.
GFR was estimated with four equations that use serum creatinine and two equations that use cystatin $C$ with creatinine (Table 1) 10,12,13,15-17 The equations are expressed in $\mathrm{mL} /$ minute/1.73 $\mathrm{m}^{2}$ and were adjusted multiplying the value by 1.73 and dividing by patient body surface area estimated with the DuBois formula.

\section{Statistical analysis}

Categorical variables are reported as frequencies and percentages and continuous variables as minimum-maximum. Bias was assessed as the median differences between measured glomerular filtration rate (mGFR, measured with iothalamate) and estimated glomerular filtration rate (eGFR, estimated with each one of the equations). Precision was defined as the interquartile range of the differences (IQRd; mGFR-eGFR). Accuracy is expressed as the percentage of estimated measurements (eGFR) within $30 \%$ of mGFR (P30). The best formula was defined as that with less bias, less IQRd (or better precision) and higher P30. Graphs were plotted comparing eGFR with the difference (mGFR-eGFR), with quantile regression lines and lines showing the $95 \%$ confidence interval (using the smoothing function in R). The confidence intervals were obtained with 1000-repetition bootstrap.

The sensitivity and specificity of each formula to classify patients with GFR values lower than $60 \mathrm{~mL} /$ minute $/ 1.73 \mathrm{~m}^{2}$ were determined. The entire analysis was carried out using the R 3.4.1 program (The R Foundation for Statistical Computing) and the RStudio software (version 1.0.153, 2009-2017 RStudio, Inc.)

\section{Results}

Thirty patients were included in the study. Patient mean age was $40.2 \pm 14.6$ years, 14 were males ( $46.6 \%)$, eight ( $26.7 \%$ ) received live donor transplant and mean time since transplantation was $13.2 \pm 10.7$ months. The main cause of chronic kidney disease was unknown in $43.3 \%$ of patients, followed by diabetes mellitus in 10 patients (33.3\%), glomerulonephritis in four (13.3\%) and other causes in three; the treatment regimens used were tacrolimus/azathioprine/prednisone in 14 patients (46.7 \%), tacrolimus/mycophenolate/prednisone in 11 (36.7 \%), cyclosporine A/mycophenolate/prednisone in four (13.3\%) and one used cyclosporine A/azathioprine/prednisone. Average GFR measured with iothalamate was $72.46 \pm 15.72 \mathrm{~mL} /$ minute $/ 1.73 \mathrm{~m}^{2}$, with a range of 46.8 to $114.5 \mathrm{~mL} /$ minute $/ 1.73 \mathrm{~m}^{2}$. 
Table 1. Equations to calculate the glomerular filtration rate

\begin{tabular}{|c|c|}
\hline Equation & Equations based on serum creatinine \\
\hline \multirow[t]{4}{*}{ CKD-EPI'10 } & - Female, $\mathrm{SCr} \leq 0.7=144 \times(\mathrm{SCr} / 0.7)^{-0.329} \times(0.993)^{\mathrm{Age}}$ \\
\hline & - Female, $\mathrm{SCr}>0.7=144$ * $(\mathrm{SCr} / 0.7)^{-1.209} \times(0.993)^{\mathrm{Age}}$ \\
\hline & - Male, $\mathrm{SCr} \leq 0.7=144^{*}(\mathrm{SCr} / 0.9)^{-0.411} \times(0.993)^{\mathrm{Age}}$ \\
\hline & - Male, $\mathrm{SCr}>0.9=141^{*}(\mathrm{SCr} / 0.9)^{-1.209} \times(0.993)^{\mathrm{Age}}$ \\
\hline \multirow[t]{2}{*}{$\mathrm{MDRD}^{9}$} & $175^{\star} \mathrm{SCr}^{-1.154} \times$ age $(\text { years })^{-0.203} \times(0.742$ if female $)$ \\
\hline & No patient was African-American \\
\hline $\mathrm{CG}^{8}$ & (140-age [years]) $\times$ weight (kilograms)/L72×SCr] $\times\left(0.85\right.$, female). In this case, CG was normalized for a BSA of $1.73 \mathrm{~m}^{2}$. \\
\hline$M C Q^{11}$ & $\operatorname{Exp}\left(1.911+[5.249 / \mathrm{SCr}]-\left[2.114 / \mathrm{SCr}^{2}-0.00686 \times\right.\right.$ Age $[-0.205$, if female $\left.]\right)$; if $\mathrm{SCr}<0.8 \mathrm{mg} / \mathrm{dL}, 0.8$ was used for SCr \\
\hline \multirow[t]{2}{*}{$\mathrm{CrCl}$} & $\begin{array}{l}\text { (Urinary creatinine }[\mathrm{mg} / \mathrm{dL}] \times 24 \text {-hour urinary volume }[\mathrm{mL}]) /(\mathrm{SCr} \text { * } 1440) \text {. } \\
\mathrm{CrCl} \text { was normalized for a } 1.73 \mathrm{~m}^{2} \mathrm{BSA}\end{array}$ \\
\hline & Equations based on cystatin or creatinine \\
\hline Stevens $3^{12}$ & GFR $=\left(177.6 \times\right.$ SCr- $^{-0.65} \times$ CysC $^{-0.57} \times$ age $\left.^{-0.20}\right) \times(0.82$ female $)$ \\
\hline $\begin{array}{l}\text { Cystatin } \\
\text { CKD-EPI }\end{array}$ & $\mathrm{SCr} \leq 0.7$ Female \\
\hline C-creatinine $e^{13}$ & $\begin{array}{l}\text { Cys } \leq 0.8: 130 \times(\mathrm{SCr} / 0.7)^{-0.248} \times(\mathrm{Cys} / 0.8)^{-0.711} \times 0.995^{\mathrm{Age}} \\
\text { Cys }>0.8: 130 \times(\mathrm{SCr} / 0.7)^{-0.248} \times(\mathrm{Cys} / 0.8)^{-0.711} \times 0.995^{\mathrm{Age}} \\
\mathrm{SCr}>0.7 \mathrm{Female} \\
\text { Cys } \leq 0.8: 130 \times(\mathrm{SCr} / 0.7)^{-0.601} \times(\mathrm{Cys} / 0.8)^{-0.375} \times 0.995^{\mathrm{Age}} \\
\text { Cys }>0.8: 130 \times(\mathrm{SCr} / 0.7)^{-0.061} \times(\mathrm{Cys} / 0.8)^{-0.711} \times 0.995^{\mathrm{Age}} \\
\mathrm{SCr} \leq 0.9 \mathrm{Male} \\
\text { Cys } \leq 0.8: 135 \times(\mathrm{SCr} / 0.9)^{-0.207} \times(\mathrm{Cys} / 0.8)^{-0.375} \times 0.995^{\mathrm{Age}} \\
\text { Cys }>0.8: 135 \times(\mathrm{SCr} / 0.9)^{-0.207} \times(\mathrm{Cys} / 0.8)^{-0.711} \times 0.995^{\mathrm{Age}} \\
\mathrm{SCr}>0.9 \mathrm{Male} \\
\text { Cys } \leq 0.8: 135 \times(\mathrm{SCr} / 0.9)^{-0.061} \times(\mathrm{Cys} / 0.8)^{-0.711} \times 0.995^{\mathrm{Age}} \\
\text { Cys }>0.8: 135 \times(\mathrm{SCr} / 0.9)^{-0.601} \times(\mathrm{Cys} / 0.8)^{-0.711} \times 0.995^{\mathrm{Age}}\end{array}$ \\
\hline
\end{tabular}

The performance of the different formulas to estimate GFR is shown in Table 2. The formula with best performance was CKD-EPI, with a bias of $-2.4 \mathrm{~mL} / \mathrm{min} / 1.73 \mathrm{~m}^{2}$, 9.6 and $96.7 \%$ precision were within $30 \%$ of the measured GFR. Cystatin C-based equations showed a poor performance. The Stevens-3 and CKD-EPI Cys-Cr equations showed high bias, low precision and lower percentages for estimating GFR within $30 \%$ of measured GFR (60 and $33.3 \%$, respectively) in comparison with the creatinine-based equations.

Table 3 shows the sensitivity and specificity of each formula to detect GFR values lower than $60 \mathrm{~mL} / \mathrm{min}$ ute $/ 1.73 \mathrm{~m}^{2}$. Eight patients had GFR measured values lower than $60 \mathrm{~mL} /$ minute $/ 1.73 \mathrm{~m}^{2}$. With MDRD, two patients were misclassified (6.6\%), with CKD-EPI, three $(10 \%)$, with MCQ, five (16.6\%), with CG, two $(6.6 \%)$, with $\mathrm{CrCl}$, one (3.3\%), with Stevens-3, two (6.6\%) and with CKD-EPI Cys-Cr, four (13.33\%).

Figure 1 shows the scatter plots of each equation and the differences between measured and estimated
Table 2. Estimated glomerular filtration rate bias, precision and accuracy

\begin{tabular}{|l|c|c|c|}
\hline & $\begin{array}{c}\text { Bias, } \\
(95 \% \mathrm{Cl})\end{array}$ & $\begin{array}{c}\text { IQRd } \\
(95 \% \mathrm{CI})\end{array}$ & $\begin{array}{c}\text { P30\% } \\
(95 \% \mathrm{CI})\end{array}$ \\
\hline CKD-EPI & -2.4 & 9.6 & 96.7 \\
\hline MDRD & $(-5.6,1.3)$ & $(5.1,13.8)$ & $(90.4,100)$ \\
\hline MCQ & 6.8 & 11.8 & 96.7 \\
\hline CG & $(3.6,11.4)$ & $(8.6,16.5)$ & $(90.5,100)$ \\
\hline CrCl & -24.4 & 12.8 & 36.7 \\
\hline Stevens 3 & $(-31.5,-19.2)$ & $(4.7,18.5)$ & $(19.2,53.7)$ \\
\hline Cystatin/creatinine & -5.9 & 12.1 & 90.0 \\
\hline CKDEPI & $(-9.7,-2.5)$ & $(3.8,19.1)$ & $(79.1,100)$ \\
\hline
\end{tabular}

$C G=$ Cockroft-Gault equation, CKD-EPI = Chronic Kidney Disease Epidemiology Collaboration equation, $\mathrm{CrCl}=$ creatinine clearance, $\mathrm{MCQ}=$ Mayo Clinic Quadratic equation, MDRD = Modification of Diet in Renal Disease study equation. 

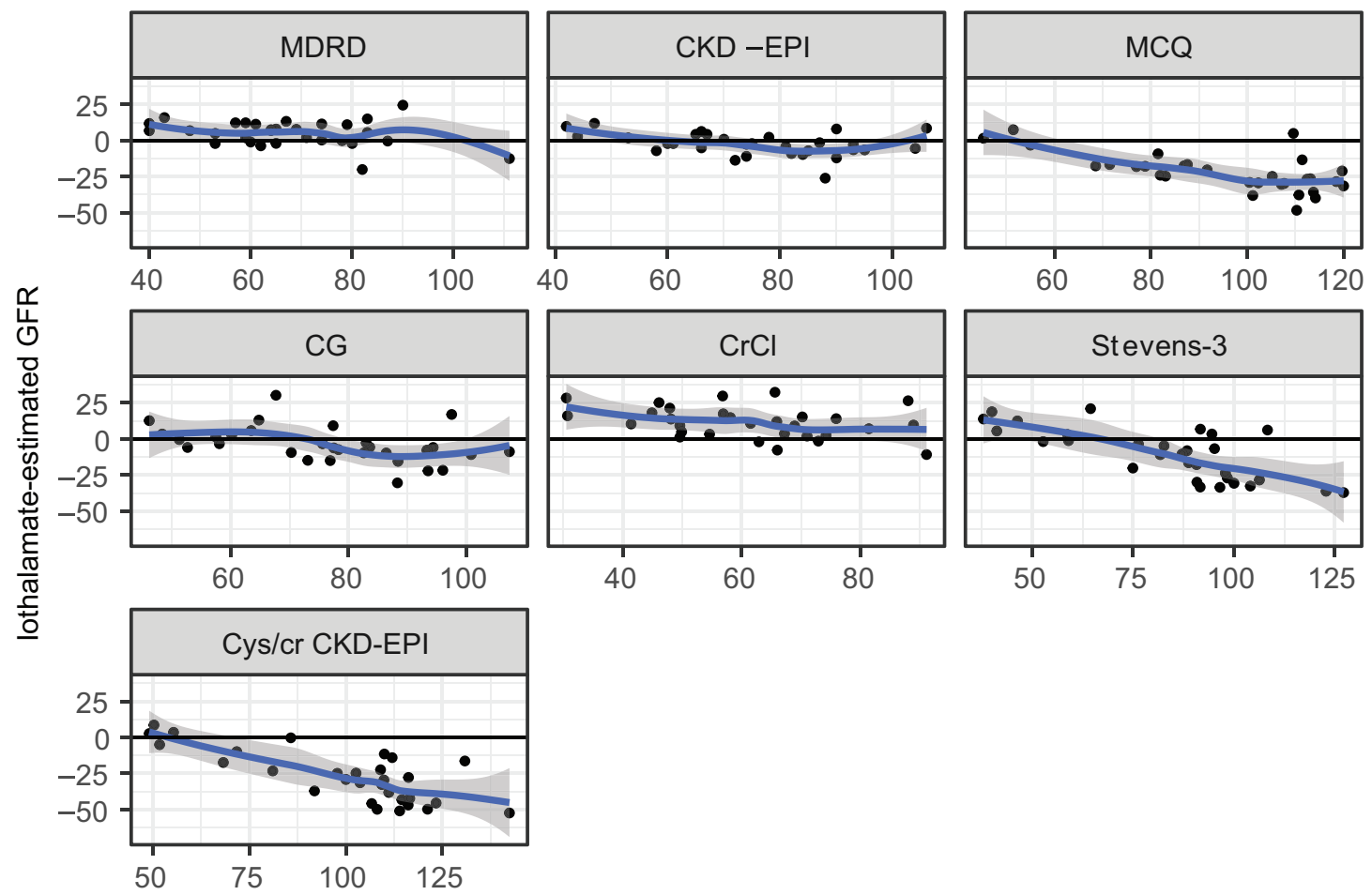

Estimated GFR

Figure 1. Glomerular filtration rate estimated by means of each one of the equations compared to the difference between iothalamate-measured GFR and GFR estimated by means of each one of the equations. MDRD = Modification of Diet in Renal Disease equation, CKD-EPI =Chronic Kidney Disease Epidemiology Collaboration equation, $M C Q=$ Mayo Clinic Quadratic equation, $C G=$ Cockcroft-Gault, $\mathrm{CrCl}=\mathrm{creatinine}$ clearance, Stevens-3 = third equation based on cystatin and creatinine according to Stevens et al., ${ }^{12} \mathrm{Cys}-\mathrm{Cr} C K D-E P I=c y s t a t i n / c r e a t i n i n e ~ C K D-E P I$.

Table 3. Sensitivity and specificity to classify patients with glomerular filtration rate values lower than $60 \mathrm{~mL} / \mathrm{minute} / 1.73 \mathrm{~m}^{2}$

\begin{tabular}{|l|c|c|}
\hline Equation & Sensitivity $(\%)$ & Specificity $(\%)$ \\
\hline CKD-EPI & $62(24,91)$ & $100(78,100)$ \\
\hline MDRD & $75(35,97)$ & $86(65,97)$ \\
\hline MCQ & $38(9,76)$ & $100(78,100)$ \\
\hline CG & $75(35,97)$ & $100(78,100)$ \\
\hline CrCl & $88(47,100)$ & $68(45,86)$ \\
\hline Stevens-3 & $75(35,97)$ & $95(77,100)$ \\
\hline Cystatin/creatinine CKD-EPI & $50(16,84)$ & $100(78,100)$ \\
\hline
\end{tabular}

$\mathrm{CG}=$ Cockroft-Gault equation, CKD-EPI = Chronic Kidney Disease Epidemiology Collaboration equation, $\mathrm{CrCl}=$ creatinine clearance, $\mathrm{MCQ}=$ Mayo Clinic Quadratic equation, MDRD = Modification of Diet in Renal Disease study equation.

GFR; the blue line on each graph shows the regression performed using quantile regression. The values above the blue line are underestimates and those below overestimate iothalamate-measured GFR.

\section{Discussion}

Currently, the search and aim in nephrology is to broaden kidney transplantation programs for the management of stage 5 chronic kidney disease. Similarly, the emergence of new immunosuppression schedules have allowed an increase in graft survival and longevity, which results in the need for tighter and more stringent kidney function monitoring.

The simplest method to assess kidney function is GFR calculation, which has multiple deficiencies; for example, its performance is different for different populations or pathologies. GFR has as gold standard for its measurement the use of inulin or iothalamate, but these methods are complex, high-priced and time-consuming for routine use ${ }^{18}$ for this reason, GFR calculations are currently used with standardized and validated formulas in certain populations in particular. By having different equations, the clinician faces a dilemma in the selection of the various equations, whether based on cystatin or on creatinine.

Management guidelines suggest that each formula should be assessed in the population where it will be used. To the best of our knowledge, this is one of the first studies to assess the equations in Mexican transplanted patients using a standard reference and with assessment methods recommended by experts. ${ }^{19}$

In the analyzed population, we found that the CKD-EPI formula had the best performance in terms of bias and 
accuracy, in addition to having high sensitivity and specificity for detection in patients with GFR below $60 \mathrm{~mL} /$ minute, and therefore we recommend it for GFR calculation in Mexican patients. However, it should be noted that practical application has some peculiarities, such as the need for having creatinine standardized, ${ }^{10}$ and, therefore, the results we describe are useful when selecting other equations such as MDRD or creatinine clearance. On the other hand, $\mathrm{CrCl}$ in this group of patients was not one of the best ways to estimate GFR.

Studies evaluating the performance of cystatin C-based formulas have shown rather variable results, mainly due to the lack of standardization when measuring cystatin $\mathrm{C}^{20}{ }^{20}$ Cystatin measurement in our study was carried out with the ELISA technique, which may have resulted in lower performance of cystatin $\mathrm{C}$-based formulas for estimating GFR, since in the development of the Cys/Cr CKD-EPI formula, calibrated or nephelometry-measured cystatin $C$ was used. ${ }^{13}$

Apart from our study, Zahran et al. also used ELISA for the measurement of cystatin $C$ to assess eight cystatin C-based different formulas; their results agree with ours in the sense that cystatin C-based equations are not superior. ${ }^{21}$

All our patients received steroids and immunosuppressive medications. Particularly, the use of steroids has been assessed by Kukla et al., who describe that steroids do not importantly alter bias or accuracy; however, there was an important drop in precision. ${ }^{22}$

The strengths of our study include that measurements of both iothalamate and cystatin and creatinine were carried out at the same time, that they were performed in a Mexican population, that standardized creatinine was used and, in addition, that GFR measurement was performed with iothalamate clearance as the reference standard. Weaknesses of our study included that it was carried out in a small population, that cystatin $\mathrm{C}$ measurement was performed with ELISA, and that due to the characteristic of being a cross-sectional study, observing the GFR variations when measured with the different formulas was not possible.

\section{References}

1. Laupacis A, Keown P, Pus N, Krueger H, Ferguson B, Wong C, et al. A study of the quality of life and cost-utility of renal transplantation. Kidney Int. 1996;50:235-242.

2. Jensen CE, Sørensen P, Petersen KD. In Denmark kidney transplantation is more cost-effective than dialysis. Dan Med J. 2014;61(3):A4796.

3. First MR. Renal function as a predictor of long-term graft survival in renal transplant patients. Nephrol Dial Transplant. 2003;18:i3-i6.

4. Fellström B, Jardine AG, Soveri I, Cole E, Neumayer HH, Maes B, et al. Renal dysfunction is a strong and independent risk factor for mortality and cardiovascular complications in renal transplantation. Am J Transplant. 2005;5(8):1986-1991.

5. Briggs JD. Causes of death after renal transplantation. Nephrol Dial Transplant. 2001;16(8):1545-1549.

6. Levey AS, Inker LA, Coresh J. GFR estimation: from physiology to public health. Am J Kidney Dis. 2014;63(5):820-834.

7. Caravaca F. Cystatin C: yes, but... Nefrologia. 2006;26:421-425.

8. Cockcroft DW, Gault MH. Prediction of creatinine clearance from serum creatinine. Nephron. 1976;16:31-41.

9. Levey AS, Coresh J, Greene T, Stevens LA, Zhang YL, Hendriksen S, et al. Using standardized serum creatinine values in the modification of diet in renal disease study equation for estimating glomerular filtration rate. Ann Intern Med. 2006;145(4):247-254.

10. Levey AS, Stevens LA, Schmid $\mathrm{CH}$, Zhang YL, Castro AF, Feldman HI, et al. A new equation to estimate glomerular filtration rate. Ann Intern Med. 2009;150:604-612.

11. Rule AD, Larson TS, Bergstralh EJ, Slezak JM, Jacobsen SJ, Cosio FG. Using serum creatinine to estimate glomerular filtration rate: accuracy in good health and in chronic kidney disease. Ann Intern Med. 2004; 141:929-937.

12. Stevens LA, Coresh J, Schmid CH, Feldman HI, Froissart M, Kusek J, et al. Estimating GFR using serum cystatin $C$ alone and in combination with serum creatinine: a pooled analysis of 3,418 individuals with CKD. Am J Kidney Dis. 2008:51:395-406.

13. Inker LA, Schmid CH, Tighiouart H, Eckfeldt JH, Feldman HI, Greene T, et al. Estimating glomerular filtration rate from serum creatinine and cystatin C. N Engl J Med. 2012;367:20-29.

14. Wilson DM, Bergert JH, Larson TS, Liedtke RR. GFR determined by nonradiolabeled iothalamate using capillary electrophoresis. Am J Kidney Dis. 1997:30:646-652

15. National Kidney Foundation. K/DOQI clinical practice guidelines for chronic kidney disease: evaluation, classification, and stratification. Am J Kidney Dis. 2002;39:S1-S266.

16. Manjunath G, Sarnak MJ, Levey AS. Prediction equations to estimate glomerular filtration rate: an update. Curr Opin Nephrol Hypertens. 2001; 10:785-792.

17. Levey AS, Coresh J, Balk E, Kausz AT, Levin A, Steffes MW, et al. National Kidney Foundation practice guidelines for chronic kidney disease: evaluation, classification, and stratification. Ann Intern Med. 2003:139:137-147.

18. Fawaz A, Badr KF. Measuring filtration function in clinical practice. Curr Opin Nephrol Hypertens. 2006;15(6):643-647.

19. Stevens LA, Zhang $\mathrm{Y}$, Schmid $\mathrm{CH}$. Evaluating the performance of equations for estimating glomerular filtration rate. J Nephrol. 2008; 21(6):797-807.

20. Delanaye P, Pieroni L, Abshoff C, Lutteri L, Chapelle J-P, Krzesinski J-M, et al. Analytical study of three cystatin $\mathrm{C}$ assays and their impact onlcystatin C-based GFR-prediction equations. Clin Chim Acta. 2008;398:118-124.

21. Zahran A, Qureshi M, Shoker A. Comparison between creatinine and cystatin C-based GFR equations in renal transplantation. Nephrol Dial Transplant. 2007;22:2659-2668.

22. Kukla A, El-Shahawi Y, Leister E, Kasiske B, Mauer M, Matas A, et al. GFR-estimating models in kidney transplant recipients on a steroid-free regimen. Nephrol Dial Transplant. 2010;25:1653-1661. 